\title{
ASPECTS OF A RHETORIC OF THE BODY AND THE LETTER TO THE ROMANS
}

\author{
Johannes N Vorster \\ New Testament and Early Christian Studies \\ College of Human Sciences \\ School of Humanities \\ University of South Africa
}

\begin{abstract}
Although the expansion of New Testament Studies to formal studies in Early Christianity and Late Antiquity have significantly changed modi of interpretation concerning Pauline material, the Cartesian effect has not been laid to rest. In addition, despite the problematisation of knowledge production which was initiated during the eighties of the twentieth century, the subject as primary originator of knowledge, born during the nineteenth century, is still haunting the production of knowledge within the field of Pauline studies, with little concern for the variety of diverse discursive practices compelling and enabling the production of a writing. Both these tendencies have infused the rhetorical paradigm within which Pauline letters have been read. I argue that a rhetoric of the body, functioning within the implicit tradition of Rhetorical Criticism, can enable the detection of discursive traces constituting a rhetoric of the body in the Graeco-Roman world. If a rhetoric of the body is used as interpretative framework for the letter to the Romans, no resistance against the Roman Empire can be discerned but rather an identification with a habitus that made a radicalisation of the Roman regulatory body possible.
\end{abstract}

Key Words: Rhetoric of the Body, Rhetorical Criticism, Judith Butler, Pierre Bourdieu, Michel Foucault, Discursive Practice, Corporal Epistemology, Romans 2-3, Romans 8, Power and Knowledge

\section{Introduction}

Within the Rhetorical Criticism it has become possible to distinguish between Traditional or Classical Rhetoric of which Modern or New Rhetoric can be seen as a re-appropriation, and Sophism or Sophistic Rhetoric, which stems from the sophistic tradition. Whereas the former was 'disciplined' into a disciplinary field (Schiappa 1992), the latter went underground, flirted and dallied so consistently with philosophy as to share the desire to generate and cultivate knowledge and can, quite often, not be distinguished from philosophy (Gaonkar 1990). Although one should be very careful not to contain these two traditions as two watertight parallel running conduits since Sophistic Rhetoric quite often informed Traditional Rhetoric and was to a large extent embraced by Modern Rhetoric, the explicit Traditional Rhetoric mostly functions in a supplemental way to another field or domain of knowledge. Its objective is not the generation of knowledge, but the management of knowledge; it functions methodologically to assist in the objectives of other disciplines. ${ }^{1}$ By far the majority of biblical rhetorical critical studies have found themselves at home within

For a more detailed, yet still not comprehensive elaboration, see Vorster (2009:508-517; 533-541). 
the supplemental tradition of Traditional Rhetoric, using especially the categories of Classical Rhetoric with the objective to understand the persuasive dimension(s) of texts from the Hebrew Bible or the early writings of Early Christianity. What I wish to do in this does not belong to what can be called classical rhetoric, or explicit rhetoric, but it belongs to what can be called implicit rhetoric of which the roots can be traced to sophism. Investigating specifically a rhetoric of the body, of which the concern is not to find a rhetoric of the body in the letter to the Romans, but to locate the letter to the Romans within a rhetoric of the body that functioned in the production of this letter. I argue that all knowledge of the body are mediated, as a matter of fact, that its materiality is culturally constructed from a diverse array of practices, not always clearly demarcated and identifiable or precisely located within space and time. Constructions of the body are never neutral, but produced by relations of power, they are also infused with rhetoric in differing degrees of intensity. A complete 'rhetoric of the body' cannot be done within the limitations of an article, but what is offered here is an attempt to demonstrate the materiality of the discursively constructed body, its existence as a product of naturalisation processes. I argue that the discursively materialised body exists as a site from which further processes of knowledge production ensue. A rhetoric of the body may enable to expose how production of knowledge, apparently having no relationship to the body, can be shown to have its origin in constructions of the body. For that reason, a rhetoric of the body is not concerned only with explicit textual references to the body, but suspects that even what are usually taken as theological statements may offer the possibility of objects of a corporal epistemology. In the first section aspects of a rhetoric of the body as a mode of interpretation are proposed. In a second section these aspects are brought to bear on selected passages from the letter to the Romans. Although the focus was on Romans 2-3 and 8, a rhetoric of the body does not require the specific demarcation of textual passages, since its concerns are those persuasive forces functioning in relations of power that constituted the text and there need not be any coherence in their operation. However, for the sake of illustration it has made more sense to restrict to particular passages.

\section{Towards a Rhetoric of the Body}

Somaticity implies rhetoricity. No body exists in isolation, but every body exists in interaction with other bodies. The interaction of bodies takes place within highly regulated everyday practices that move, attract, coerce to act and make according to what 'ought to be.' In a very physical manner the Roman practice of swaddling their children with the objective to ensure strong, upright bodies is an example of a rather violent form of persuasion at a still very tender age. To an extent it symbolises the manner in which bodies were materialised and shaped to align with social normativity (Rouselle 1988:52-54, 57). When these Roman bodies grew a little older, other practices, such as "blows, threats, reprimands and admonishments" may be implemented in order to "make their bodies healthy and attractive and their characters docile and obedient" (1993:54). ${ }^{2}$ The materialisation of bodies in a community happens according to an already existing constructed regulatory body which came into existence over a long period of time via the consistent reiteration of practices that were required by the particular community. It is a process that commences at birth and continues even into after-life, if a culture so decides.

One such domain of bodily interaction is our sexuality. Judith Butler radicalises this rhetorical force when she renders the materiality of 'sex' dependent on "highly regulated

2 Rouselle (1988:54) quoting from Oribasius Lib. In.17. 
practices." She writes: "Thus, 'sex' is a regulatory ideal whose materialization is compelled, and this materialization takes place (or fails to take place) through certain highly regulated practices" (1993: 1), and in her project of redefining the materiality of the body she sets as one of her objectives "the recasting of the matter of the bodies as the effect of dynamic of power, such that the matter of bodies will be indissociable from the regulatory norms that govern their materialization and the signification of those material effects" (1993:2). Bodiliness is constituted by the possibility of rhetoric. If the body is constituted by regulatory practices as a normative ideal that governs the body which it produced, the body cannot but be rhetorical.

Although not always articulated as rhetorical, those who work on the body consistently appropriate the technology of rhetoric in explaining the construction of bodies. What can be identified in Butler's compelling materialisation of bodies as a persuasive force making a culturally desired body derives already from Foucault. ${ }^{3}$ If there is indeed a person who can be identified with the notion of discursively constructed bodies it would be Foucault (see also Butler 1989:601). To attain a better understanding of Foucault's views on the body, it can be approached from his work on sex. When he sets out to write the History of Sexuality he wants to define the "regime of power-knowledge-pleasure that sustains the discourse on human sexuality," and to see how "sex is "put into discourse" (1978:11). Tracing the development of the confession to the Christian pastoral, with reference both to asceticism and monasticism, he writes: "An imperative was established: Not only will you confess to acts contravening the law, but you will seek to transform your desire, your every desire, into discourse... The Christian pastoral described as a fundamental duty the task of passing everything having to do with sex through the endless mill of speech" (1978:21). Putting the body into discourse means to grant the body a discursive existence and to find in its discursivity the very basis also of its materiality. Foucault's concern is not the prediscursive but the discursively constructed body, which does not mean a denial of a natural body's existence. Towards the end of History of Sexuality he invents an imaginary interlocutor accusing him of not allowing for the existence of a 'biological minimum: organ, instinct, and finality' (1978:151), that is, of the existence of sex as foundational, as biological with a diversity cultural or historical manifestations. Foucault did not deny this allegation, but questioned whether the question should be asked in this manner, that is, that "an analysis of sexuality necessarily imply the elision of the body, anatomy, the biological, the functional?" This allegation is denied (1978:151). Yet this does not imply on the other hand that the body (or in Foucault's case, sex) should be seen as biological, preceding its historical manifestations. It is the Biology versus culture dichotomy that should be problematised (Oksala 2007:75). As a matter of fact, analysing the manner in which the body or sex was and is put into discourse, should render a visibility of the body, without pretending a fundamental body in itself, ${ }^{4}$ or a body who functions as agency in the making

Biesecker (1992:352) also mentioned difficulties in determining Foucault's view on the role of rhetoric, since he seldom foregrounded a disciplinary demarcated notion of rhetoric. And when he explicitly refers to rhetoric, he constrasts rhetoric with parrhesia, the former associated with the 'continuous long speech,' with an incapability of truth-telling, with artificiality, while the latter with 'dialogue' as 'major technique,' truthtelling, not figurative but natural (see Foucault 2001:9-10); he also appears to restrict rhetoric to speech in contrast with writing (see Foucault 1988:27). See also Tell (2010:97), who demonstrates the rhetorical modality in which Foucault works; see also Condit (1999:329-330) who offers Foucault a limited position within material rhetoric.

4 According to Foucault it is the 'idea of sex in itself' that should be problematised, because it is power deployed by the discursive practice of sexuality that directs towards sex as an anchorage which supports manifestations of sexuality (1978:152). 
of cultural and historical manifestations (Foucault 1978:157). In his analysis of the memoirs of the hermaphrodite Herculin he points to the manner in which the then medical practice actually submitted the very real hermaphroditic genitalia as an anatomical deception, convinced of the existence of a 'true sex' as normative, thereby rendering any socalled deviation an aberration. This had to be disguise of nature (Oksala 2007:73). ${ }^{5}$ What Foucault points us to is to see the 'biological' as a discursive practice, implanting and distributing its own categories as to be taken as 'normal' or 'natural.' Whereas Biology may be one such discursive practice, a variety of discursive practices function in the construction of the body, effectively yielding or producing a normative ideal in society, or to put it a bit differently (albeit still within Foucault's terminology), forming the body as an object of knowledge, establishing this unity from the input of a variety of social spheres, thereby lending it a fixity, a stability, creating the idea of a true, normal, natural body. It is this constructed body who features as 'real' body at particular moments in history, and it is the reproductions or effects of this constructed body, that is confused as causes that can be assigned to an ontological natural body. ${ }^{6}$

As a product of a variety of discursive practices the constructed body functions as an explanatory framework infusing the body with a system of knowledge and meaning. ${ }^{7}$ It makes the body into a site of signification, a site of political communication. Putting the body into discourse makes the body into a site which functions as a site for 'implantation' or 'inscription' for regimes of discourse and power. Discursively formed as an object of knowledge, it simultaneously functions as a site for discursive struggles, contestations and conflicts entrenching dominating discourse as true, or normal while excluding others. In its discursive existence the body becomes part of a political technology of the body by means of which regulative ideals are implanted as 'normal' or 'natural,' thereby rhetorically enhancing their persuasive power. ${ }^{8}$ If rhetoric is not restricted only to traditional rhetoric, but

5 Oksala (2007:73) quotes from Foucault's Herculine Barbin: Being the Recently Discovered Memoirs of a Nineteenth-Century French Hermaphrodite, inter alia, the following: "He (sic) [the doctor] had, as it were, to strip the body of its anatomical deceptions and discover the true sex behind organs that might have put on the forms of the opposite sex. For someone who knew how to observe and to conduct an examination these mixtures of sex were no more than disguises of nature."

6 See in this regard Mills (2003:83) who indicates that with Foucault bodies are "always experienced as mediated through different social constructions of the body." See also Mills (2003:56) where she explicitly argues that "Foucault is not denying that there are physical objects in the world and he is not suggesting that there is nothing but discourse, but what he is stating is that we can only think about and experience material objects and the world as a whole through discourse and the structures it imposes on our thinking."

7 See in this respect Gaca's treatment of Plato's regulating sexual principles (2003:23-58). She indicates how Plato problematises sexual desire in terms of the dangers it entails for the order of the polis and the state. Bodily sexual desire is fitted into an explanatory framework linking discourses concerned with health, with city politics entrenched in a hierarchy of superior versus inferior bodies, whether of class or age, with more procreative leniency granted to the former in the hope of producing better specimens, with disorder and crime, with economics and population control and also linking it to discourses with religion and customs. Plato contributes to the creation of an explanatory framework substantially transforming sexual desire into a negative human capacity to be politically regulated for the benefit of the city.

8 Mills (2003:93) explains how feminists have shown the notion of 'femininity' to be a disciplinary regime writing its regimen of "depilation, cosmetics, exercise, dieting and attention to dress" on to the bodies of women. Enquiring the construction of the male body in antiquity, Gleason (1995:63) refers to Polemo who pointed to the 'signs' by means of which different kinds of androgynoi could be distinguished. The softer, more effeminate can be spotted by a "small rounded chin; soft unstable knees, "fleshy hips; and a fluid gait in which no part of the body holds still." A 'real' man on the other hand was signified by his upright posture, symmetrical physical attributes, his balanced, slow step, low voice, measured speech, steady eyes exuding a courageous gleam, in short by his control over his body and especially also by the absence of effeminate signs 
is seen as functional in the production of knowledge, a rhetoric of the body's concern becomes the mechanisms by means of which the body becomes constructed, the manner in which "regimes of discourse and power inscribe themselves" upon the body (Butler 1989: 601), the way in which an incorporation of bodily classifications and categorisations take place, in short, how the body is materialised as both a product of power and productive of power.

It would already have become clear by now that putting the body into discourse also implies its subjection to relations of power. As a matter of fact, discourse is instrumental in the transmission and production of power. Foucault writes that it is "in discourse that power and knowledge are joined together" (1978:100). And he continues: "Discourse transmits and produces power; it reinforces it, but also undermines and exposes it, renders it fragile and makes it possible to thwart" (1978:101). According to Foucault, power is never unidirectional or -lateral. The traditional view that power always functions repressively is to be departed from, since power is always everywhere and operates also from everywhere. Instead of identifying power with repression, hegemony or consistent domination, the productive nature of power should be considered. ${ }^{9}$ In pointing to Foucault's insistence on power as productive, Biesecker (1992:355), quoting from Gayatri Spivak, problematises the direct translation of the French pouvoir into 'power.' There is in the word pouvoir a certain 'can-do-ness.' If this component of power is taken into consideration in the combination power/knowledge Spivak, as quoted by Biesecker, contends: "if the lines of making sense of something are laid down in a certain way, then you are able to do only those things with something which are possible within and by the arrangement of those lines." And Biesecker interprets that "power names not the imposition of a limit that constrains human thought and action but a being-able that is made possible by a grid of intelligibility" (1992:356). A discursive practice therefore provides not only with statements, not only with language, not with ideology or simply hegemony, but with an explanatory framework defining and demarcating a particular 'can-do-ness.' Discursively writing on the body then implies not necessarily repression, but production, the possibility for the deployment of co-native modalities, such as resistance, counter-action, modification. The 'lines of making sense' or the image of normality which power has transmitted through discourse are therefore not irrevocably fixed and impenetrable in their claims, but they simultaneously provide the possibility to resist, albeit from within, albeit problematising the quality of 'making sense,' albeit not from the resisting subject as original source of resistance. ${ }^{10}$ A rhetoric of the body is concerned with the strategies, not only with power investing itself on bodies through discourse, the 'can-do-ness' evoking new possibilities, but also the possibilities of resistance that can be realised within the lines that make sense in a society.

It is with Bourdieu that the rhetoricity of bodiliness is given the most explicit articulation. He writes: "Every social order takes systematically advantage of the disposition of the body and language to function as depositories of deferred thoughts that can be triggered

(Gleason 1995:60-62). Physiognomics provided with a tool for understanding the rhetoric of the body in antiquity (see also Gleason 1995:58).

9 Foucault writes: "relations of power are not in super structural positions with merely a role of prohibition or accompaniment; they have a direct productive role, wherever they come into play" (1978:94).

10 Biesecker indicates that resistance becomes a possibility within the Foucaultian power/knowledge combination on condition that 1 . Resistance comes about within the already established lines of making sense and not from independent outside sources; 2 . the resistance does not make sense within the lines of making sense, that is, that it cannot be accommodated; 3. the possibility of resistance already resides within the possibility to 'break' the lines and not in the resisting subject as source of resistance, subjectivating the subject as effect (1992:357-358). 
off at a distance in space and time by the simple effect of re-placing the body in an overall posture which recalls the associated thoughts and feelings, in one of the inductive states of the body, which as actors know, give rise to states of mind." He then shows how the symbolic order is recalled not only in great collective ceremonies, but also in what can be called the "less invisible intention of ordering thoughts and suggesting feelings," not only in practices, in the arrangement of thought, but also in "bodily expressions of emotion of laughter or tears" (Bourdieu 1990:69).

Bourdieu decisively takes leave of and disposes of the dichotomy between mind and body, when he insists on the primacy of the interaction between practice and what he calls the habitus. The production of knowledge does not take place in a passive recording of the objects of knowledge, but in practice where knowledge is constructed via the principle of habitus. The principle of habitus is already an embodied product, produced by conditionings underlying the particular conditions of a practice. As such habitus is that "system of durable, transposable dispositions, structured, structures, predisposed to function as structuring structures, that is, as principles which generate and organize practices and representations" (Bourdieu 1990:52). If we were to translate this into the paradigm of a rhetoric of the body, habitus can already be seen as an effect of persuasion, of the way in which the symbolic order of a society has effected a particular embodied predisposition. On the one hand, therefore, it would be possible to speak of the somaticisation of the habitus, since its very formation is relative to bodily practices, to histories representing the interaction of bodies. But it also makes sense to speak of the manner in which bodies have been habituated. Habitus is the embodied history of a community, it refers us to the bodily predispositions that are simply taken for granted, that are experienced as natural, and therefore seldom proposed as subject for argumentation.

Its rhetorical effect on the body is such that it infuses and controls bodily experience and behaviour. For that reason, Bourdieu can write (and I quote in full owing to its appropriateness): "Symbolic order works partly through the control of other people's bodies and belief that is given by the collectively recognized capacity to act in various ways on deep-rooted linguistic and muscular patterns of behaviour, either by neutralizing them or by reactivating them to function mimetically".

Adapting a phrase of Proust one might say that arms and legs are full of numb imperatives. One could endlessly enumerate the values given body, made body by the hidden persuasion of an implicit pedagogy which instills a whole cosmology through injunctions as insignificant as 'sit up straight' or 'don't hold your knife in your right hand,' and inscribe the most fundamental principles of the arbitrary content of a culture in seemingly innocuous details of bearing or physical and verbal manners, so putting them beyond the reach of consciousness and explicit statement.

Using Foucault, Bourdieu and Butler in an attempt to theorise a rhetoric of the body allows at this stage the following. ${ }^{11}$ Firstly, a rhetoric of the body enables us to enquire as to the processes by means of which culture is naturalised. There is perhaps no persuasive technique as intense, as persistent in its insistence as when the body is evoked as site for the installation but also contestation of values. A rhetoric of the body insists that this process of naturalisation, whereby culture is turned into nature, whereby history is embodied, and

11 The objective is not at this stage to precisely differentiate between categories such as, for example, habitus and épistèmé, Bourdieuan principles that generate practices and Foucaultian discursive practices, but to create an awareness for the formulation of rhetorical strategies made possible by the work of Foucault, Bourdieu, Butler and others working more or less within the same paradigm. 
whereby values are bodied forth, be taken into consideration. This is even more the case when it is considered that the distinction between nature and culture we make today, was not made in the same manner in antiquity (Flemming 2000:7-14). What we take to be social facts were seen as natural - the current distinction into two levels with the natural serving as feeding soil for the cultural, but also as rhetorical enforcement did not always feature in antiquity where social facts, cultural constructions were taken as natural; there was simply no natural sciences of which the institutionalisation only commenced between 1780-1850. Although caution should be exercised in studies concerned with antiquity not to equate the same valorisation between culture and nature contemporary science bestows on this dichotomy, a rhetoric of the body's concern is the exchange and transference of values in processes of naturalisation and the construction of culture. ${ }^{12}$

Secondly, a rhetoric of the body also compels us to enquire how the body is constituted as an effect of power relations. Butler tells us that it is the materiality of the body, as an effect of a process of materialisation which is power's most productive effect. It is the materialised body that functions as a regulatory body simultaneously producing bodies that it also governs and regulates. As such the materialised body assumes normative status; this is how a body should be and when enforced with an argument from 'nature' it becomes how a body in fact is. It is this normative status given to the materialised body which simultaneously functions to construct an exclusionary matrix. Whatever construction of the body is made not conforming to the regulatory norms that materialised the body, will be seen as abnormal, defect, imperfect, disabled or even unnatural. To put it in Butlerian terms: the materialised body serves to demarcate, to circulate and to differentiate bodies (1993:1), thereby affirming what is regarded as normative while at the same time functioning to exclude.

A rhetoric of the body compels therefore on the one hand to enquire as to those discursive practices that have produced the materialised body, and on the other hand to enquire also to the reproduction of the body. However, there is more. The materialised or habituated body assumes epistemic status. If values are bodied, histories embodied, symbolic order bodily affirmed, a rhetoric of the body compels to enquire the interaction between knowledge production and the body. The materialised body is product of relations of power, but it is also at the same time, site for the production of power/knowledge. As normative signifier it is used in the production of knowledge, in providing a rationale for the symbolic order, and its normativity privileges certain discourses of knowledge while excluding and rejecting other possibilities.

So even before a rhetoric, a rhetorical paradigm is implemented, a rhetoric of the body has already predisposed that particular paradigm; the values that were given body by habitus, have already regulated rhetorical practice, have already persuaded to construct in a manner that would safeguard and guarantee certain values, certain knowledges while excluding others. It makes therefore little sense to do what New Testament rhetorical critical scholarship does, namely to analyse New Testament material in terms of what is

12 This is still a problematic area. Although it would make sense that the contemporary distinction between culture and nature was not made since everything, every social construction (fact) was taken to be nature, using the natural as fortifying mechanism for an argument cannot be denied (see in this respect Flemming's discussion of Laqueur and her discussion of Aristotle's views on the naturalness of slavery (2000:9-28). In addition, the distinction between physis and nomos, pre-existing the advent of sophism, but functioning as topos within sophism may not be exactly the same as the 'nature versus culture' debate, but can definitely be seen as precursor to this debate. It existed since the days of sophism, although admittedly with different meanings assigned (see also Dillon and Gergel 2003:xv-xvi). 
called Classical Rhetoric, except if with the intention to identify and label particular rhetorical techniques. The rhetorical techniques provided by these systems have already been predisposed by a rhetoric of the body; its topoi, its argumentative techniques, its phases have already been infused by values concerned with the body.

This brings us to a second aspect, namely the corporal nature of rhetoric. It was Protagoras, sophist from Abdera (490) who already maintained that "man is the measure of all things," and he linked the soul, as a corporal entity, to the senses. Truth does not determine 'man' but man as body determines truth. According to Glancy, following Gleason, Roman rhetoric can be seen as a 'corporal technology of masculinity.' This was the provenance of the Roman elite man. Training in the rhetorical implied embodied encoding of the patriarchal values of classical antiquity. For example when Cicero addresses his son he writes: "But as for us, let us follow Nature and shun everything that is offensive to our eyes or our ears. So, in standing or walking, in sitting or reclining, in our expression, our eyes, or the movements of our hands, let us preserve what we have called "propiety" (Glancy 2010:13). In a similar manner can Quintillian be quoted when he warns the budding male rhetorician to consider his gestures and avoid what can be taken to be effeminate.

There are several implications that the link between a rhetoric of the body and the study of early Christianity may have, but I wish to draw attention to only one. Owing to the emergence of the subject as the primary originator of knowledge during the $19^{\text {th }}$ century, owing to a succession of preservation mechanisms linked to emergence of canonicity, moving from the preservation of the biblical writings as sacred magic, and the preserve of the church, to the preservation of biblical material to the elite of the $19^{\text {th }}$ century and the preserve of biblical writings by biblical scholars, the focus was on the text and its agency. Knowledge production and the safeguarding of a particular type of knowledge production centred around the text. Even in historical studies, the objective was either to understand the origins of the text, or the relationship between signs in the text and the circumstances of the text.

Although I do not wish to belittle these stages in the production of knowledge, this tyranny of the text entailed not only an impoverishment of the wide and deep tradition of early Christianity, but it also neglected the performativity of the text as part of discursive practice. A rhetoric of the body allows for this shift from an exclusive focus on the text to a consideration of the text as a product of a vast array of power relations. It compels us to consider the text as one node, one minuscule element in an array of configurations that not only produced the text, but also allows its performativity. Instead of using the text as point of departure, the body is submitted as normative signifier in early Christianity. This will also allow for the re-integration or reclaiming of those texts that have not been canonised.

Allowing the discursive practices that have informed the constructions of body to formulate our strategies of interpretation, bring us into contact with what Bourdieu has called the rules of the game, those underlying regulatory patterns, that nobody questions, but which determines what we do. From a rhetorical perspective it enables to discern the tropological, more particular, the metonymical in the explanatory frameworks that have been constructed and implanted on the bodies of early Christians. If we paraphrase Dave Tell's interpretation of Foucault a rhetoric of the body enables us to see how an explanatory framework, a discursive practice compelled to look beyond the body, beyond the bodily act or process, how it implants a "conceptual origin that purports to explain the cause and meaning" of the body and its actions, and it helps us to see how this implanted conceptual 
origin, after its implantation "renders the subject vulnerable to new modes of power" (2010:108-109).

\section{Readings of the Romans Letter from a Perspective of a Rhetoric of the Body}

\section{Circumcision and Romans 2-3}

The interpretation of Romans 2-3 is besieged with political correctness in attempts to safeguard and protect Paul from anti-Semitism, yet again operating on the assumption of a great man functioning as a primary originator of knowledge, thrusting full accountability on Paul's shoulders for the production of knowledge. It has by now become commonly accepted that Romans 2-3 functions within the broader ambit of the diatribe, and evokes more specifically the rhetorical technique of the apostrophe (Stowers 1979; Dunn 1988:77160, 184-194; Jewett 2007:25-27, 193-267, 294-305). As with so many other rhetorical techniques employed by Paul, his adherence is general, that is, certain features are used. According to a Quintillian interpretation of the apostrophe, this technique features in discourse (speech) when the orator manages a 'turning away' from the audience. That is, a little scene is enacted with an imaginary interlocutor and a debate concerning a particular issue is put on to the table. It usually happens as an expression of pathos, signifying an appeal of desperation (Lausberg 1998:338, but see also 339-344).

For New Testament scholars it has become a favourite pastime to attempt identifying the imaginary interlocutor. The little scene enacted is usually divided into two sections, namely 2:1-16 and 2:17-29 primarily on the basis of a differentiation in the addressees, the first seen as a continuation of 1:18-32 which surprisingly is continuously seen as referring to non-Christianised, non-Jews, and the second as referring to the Jew, who is then quickly heterogenised so as to protect Paul from anti-Semitism. This is then usually followed up by detailed exegesis teasing out apostrophic elements, unfolding meanings based on textual, historical and theological relationships.

What seldom features is how a rhetoric of the body operates in this section despite of the abundance of signifiers to bodiliness. ${ }^{13}$ In determining signifiers concerned with the body, the problematic Cartesian differentiation between body and mind should be avoided, since what may appear to us as emotional, rational, spiritual or psychological was often in antiquity simply physical. For example: irrational behaviour could be related to a disturbance of correct proportions of humours in the body, or it could be seen as an inclination to an imbalance of the fundamental constituents of bodily fabric, quite often as an invasion of external environmental elements. In a woman, who was usually associated with irrational behaviour and with outbursts of emotion, excessive moistness was usually referred to as the culprit (Carson 2002). Despite the default inclination to a violent ethos in antiquity, excessive anger in a male, the inability to self-control, signified a flaw in what constituted a real, balanced man. In a similar manner should reputation not be completely divorced from

13 Bodily signifiers already commenced in 1:18-32 (and it would even be possible to find the body signified in the very second word of this letter, namely 'slave,' which refers primarily to an inferior bodily constitution see again Flemming 2000:9-28; also Glancy 2010:43-53, 62-65). Restricting ourselves only to 1:28-32, terms referring to the body can be seen in the following: 'a based mind' is expressed in inappropriate bodily behaviour; the body is seen as container that can be filled, and in almost tautological fashion the bodies of the 'they', that is, the outsiders are filled to the brim with licentiousness, greed, jealousy, death, strife, deceit in various formulations, a puffed-upness, foolishness, unreliability, all terminologies signifying a body out of sync, out control, given over to excess. This is then assigned to the collective 'you' of chapter 2. 
bodiliness. 'Honour' for example was not only an achieved condition, but it was thoroughly infused with manliness and being dishonoured relegated to the sphere of the effeminate, or the alien.

Various aspects of the body can be referred to in Romans 2-3. However, we should first recognise the use of apostrophe. In the turning away from addressing the audience and enacting this little scene, Paul assumes the role of the orator, interrogating an imaginary interlocutor of whom very little interlocution can actually be seen. In assuming the role of the orator, Paul simultaneously displays himself as the vir bonus, since not only was oratory a distinctive characteristic of the elite Roman male, but in this instance it probably also signified a man in complete self-control. Oratory as a specific male characteristic was seen as the product of a self-disciplined, self-controlled life. Mastering the body was implied in oratorical practice even to the extent of gestures and voice. Vander Stichele and Penner quoting Gunderson, who quotes Quintilian, show that the "orator's body was to exhibit the vir bonus which denoted ideal masculine control in performance." Enacting this scene where the encoded author can be identified with the orator, re-inscribe the normative male body in control. At the same time, the addressee (within the framework of the diatribe and not to be confused with the implied audience) is portrayed in denigrating fashion, also typical of controversia speeches" (2009:69).

It is worth looking at the manner in which the addressee's body functions as site of knowledge on which the orator's allegations are based. Not the external surface of the body, but the interior or recessive body ${ }^{14}$ is put into discourse when the addressee's heart is inscribed as 'hard' and 'unrepentant' (2:5). In Judaism as in early Christianity the heart was a bodily part with popular, epistemic status. The 'perfect heart' could be seen as normative ideal, functioning as part of regulative practices that materialised the true Jewish male body. During the Hellenistic era, medical and philosophical discursive practices yielded different traditions on where to situate the seat of reason. For some it was the brain, but for others again it was the heart or at least fluid encircling the heart. ${ }^{15}$ Although not completely centred in the body, it was thought to be centred, thereby revealing the essential core of a person. The perfect heart as normative ideal signified manliness specifically in its manifestation of reasonableness, but also as indication of courage and life-giving power. However, there was also an element of sociality inscribed on the perfect heart; it served to signify group solidarity, a token of Mediterranean hospitality, a striving towards inclusiveness. Predominant characteristic of the perfect heart was a moral and reasonable lifestyle described as "walking in singleness of heart" Brown 1988:33-44. Metonymically "walking in singleness of heart" counts for the upright, active, transparent and reasonable morality of the Jewish male. The implantation of a moral discourse, searching for the essence of the moral person, exerting a claim on a natural superior ethnic identity, fully permeated by radical manliness found in the heart and its functions an ideal organ. The ethnic location of the body can be known by a summoning of the interior body. ${ }^{16}$ Capitalising on what was

14 See Malul (2002:260). The heart belongs to the "innermost organs which is thus impenetrable and unknown," and yet the explanatory framework, the discourses of ethnicity, morality, and gender render it "visible.' Since it is actually only 'God' who can know what is in the heart (see also Rm 2:5), it becomes a site for the inscription of ultimate values.

15 See also the discussion in Martin (2006:108-111).

16 There are several accompanying aspects that should perhaps also be considered. Hardness of heart suggests impenetrability - it is therefore manly, but to the exclusion of Mediterranean hospitality (see Brown 1988:36); according to Brown, the "religious ideal of the 'perfect heart' was intimately connected with hopes for an ideal society that poignantly reiterated in Jewish and Early Christian texts," which fits the context in this case 
made of the heart, moral discourse could explain its condition by a surveillance of moral behaviour.

Summoning a rhetoric of the body with which the Jew and the emergent early Christian would have been familiar, the orator introduces an argument of incompatibility indicating an inversion of the social order on account of the addressee. In this case it appears as if the seat of reason was caught up in a dualism, a conflict, not reflecting a "walking in the singleness of heart." ${ }^{17}$ What you see, is not what you get; appearance does not correlate with reality; there is a veiledness, a mask, an image that does not correlate with the normative ideal of the innermost body. The dualism evoked yields a person deceptive to the core of his existence. Brown indicates that the "human heart might harden: it could become a heart of stone" and this hardening of the heart disclosed resistance to God's will (1988:35). ${ }^{18}$ We find ourselves within the language of identity formation; the boundaries that demarcate the true Jewish male have been transgressed. The rejection of this privilege, the inversion of this 'divinely' socio-political order will make them the target of God's wrath.

It should of course be kept in mind that Paul could not see the interior body, let alone the heart. Neither whether it was hardened. Yet the explanatory framework that was already in place in Judaism, implanting on the heart the normative ideal of the true Jewish male, serves to explain an essential identity gone wrong. Visible bodily offensive behaviour functions as epistemic, functions as a source of knowledge, exposing a 'malfunctioning' interior disposition. The denigrating is expressed in the construction of bodies that do not belong to those of the 'insiders.' Their exclusion of others will summon their own, entailing loss of status, again articulated in bodily terminologies.

The heart features again (2:15), and the 'walking in singleness of the heart' again hovers in the background, albeit not expressed. Located in the recessive body with its characteristic darkness, mystery and inclination towards disorder and uncontrollability, the heart has in this case been brought under control, thereby responding to the 'natural' social-political order of the wise, true, male Jew. We recognise what Biesecker (1992:357) has indicated concerning resistance. This is not a counter-attack, but the same 'grid of intelligibility' is used via the exposure of incompatibility on the side of those identifying with the dominant discourse. Moreover, although "resistance names the non-legible practices that are performed within the weave," it is at the same time asymmetrical to it. Finally, the orator, who can in this case be seen as the one who is resisting, is not the origin of critique, but is also an 'effect of force relations,' fully identifying with the explanatory framework within which the 'heart' has been located.

A different bodily part dominates in the resumption of the apostrophe in 2:17-29 providing a glimpse of how a construction of the body structured the symbolic order. This passage demonstrates to what extent social order has been constructed and meaning allocated around a logic of the phallus. The issue at stake is circumcision. Few bodily practices so clearly illustrate the metonymical as circumcision. To paraphrase Tell $(2010: 107)$ in a different context, looking beyond the act of circumcision itself, the discursive practices of canonised writings, 'divine' commands, myths, rites implant a "conceptual origin that

quite well (here they are portrayed as causing strife $2: 8$ ). The rebelliousness of the resistor can be seen not only in disobedience (see $2: 8$ ) but in an attempt to usurp the function of God as the judge.

17 See for example the use of I og i 1 oma i $(2: 3)$.

18 Hardening of the human heart signifies therefore a rejection of the social order, a rebellion against a privileged socio-political position. 
purports to explain the cause and the meaning" of this penis-changing, or penis-modifying act. Once this implantation has happened, a discursive site has been constructed for the production of new modalities of power (2010:108). Implantation happened with such a persuasive force that the 'looking beyond' becomes an overlooking, that a certain detachability from the violence of this act has been observed (Greenblatt 1997:221-222).

According to Malul, the physical act of removing the foreskin should be associated with the notion of 'exposure,' that is, making known what has up to the moment of circumcision been held as unknown, concealed and hidden (2002:400). Putting it a bit differently, integrating Eilberg-Schwartz's insistence on ethnic patrilineality, ${ }^{19}$ ethnic location can be known, is uncovered by the circumcised penis. As such, it is not a rite of signifying descent, but a rite of signifying alliance with a particular group - "it had become a rite of legitimizing newcomers into the covenant community, rather than [only] into the smaller kin group of the family" (2002:400) and it is only after this rite has been performed that the newborn will be recognised as legitimate member of the social group. However, this 'uncovering' or exposure concretely catapults the subject to a different hierarchical level, because it differentiates from female members who have vaginas; via circumcision, the newborn does not only become a legitimate member of the social group, but enters as a male member, that is, on a level that cannot be achieved by the female (2002:401-402). It therefore signifies not only ethnic location, but also social location.

Whereas the exposed penis assigned status, the exposure of female genitalia was seen in a pejorative sense. For that reason, the terminologies used to refer to the uncircumcised state attached the same "pejorative connotations that were attached to the vagina" (2002:403). Moreover, the uncircumcised penis not only located a man within the realm of the 'other,' but also signified a loss of descendancy (Eilberg-Schwartz 1990:148) ${ }^{20}$ Corporal epistemology is confirmed when the foreskin is metaphorically used to signify a blockage of knowledge and rationality. Malul indicates that the "very apparatuses of the epistemic process," namely the 'ear,' 'eye,' the 'mouth,' and the 'heart' are semiotically interrelated to the uncircumcised, and to lack of knowledge by the use of the same lexeme referring to the foreskin (orla - 2002:404-407). Just as the ear will earn the capacity to hear by the removal of this covering, so will the penis. This state of not knowing, of not having the foreskin removed, can also be collectively applied to the nation of Israel as a whole.

The rite of circumcision was therefore quite radical, because not only did it signify membership to a social group, but it also 'uncovered' as a male, it also publicly made the newborn known and transferred from the state of the unknown to that of the known, the recognised members of the in-group, and it also signified an obligation to perpetuate the social group in future. The body from whom the foreskin of the penis has been removed, is a body in the know. Circumcision, infused with the notion of uncovering what is hidden and concealed, of making known and confirming rationality, translates on to a sociological level, where males are given superior status and the right to dominate on the basis of being

19 On the penis as such, Schwartz (1990:145) writes: "The penis, then is what makes a boy a male, an adult, a father, and a continuator of his lineage... [O]ne must have a member to be a member," where the explanatory framework for the elevation of the penis refers to the 'boy's emerging masculinity (gender), line of descent (genealogy), and social intercourse (sociality).

20 Eilberg-Schwartz (1990:148) suggests that the "shall be cut off from his people' commanded by Gn 17:14 can also apply to the possibility of cutting off descendancy. Malul (2002:396-399) criticises EilbergSchwartz's insistence on the circumcision as primarily signifying fertility and the 'ability to perpetuate a lineage of male descendants" (Eilberg-Schwartz 1990:143). Although the focus of Malul on the circumcised penis as signifier of the capacity to 'know' and 'be known' should be foregrounded, the duty of procreation cannot be excluded from its signifying function, albeit as ethnic obligation. 
'in the know'; on the other hand, it also makes known those who are inside, thereby differentiating from the unknown outside world. The symbolic order, both in terms of social location within the group, as well as in terms of ethnic location in its differentiation with the outside world, in addition to a whole system of codification maintaining this order, can therefore be "predicated upon and symbolized by the structure and functioning of the human physical body" (2002:408). Yet, the circumcised penis is not only product of power; it is simultaneously also productive of power because within the 'sense-making' that these lines provided, a certain 'can-do-ness, ${ }^{21}$ a particular capacity is developed, namely the capacity of being able to know, being able to identify and conduct oneself according to what is taken as truth, being able to be a man and fulfill the duties and obligations required by a man, being able to be (in this case) a Jew and duly differentiate the self from the other.

It is in this phallogocentric symbolic order in which Paul's debate should be seen. The association of circumcision and knowledge can clearly be seen when the 'advantage' or the 'value' of circumcision for the Jew is problematised (3:1) but relativised by maintaining the link with knowledge when the primary benefit is seen in knowledge being divinely allocated to the Jewish nation (3:2). The regulatory power of the phallogocentric should not be underestimated in the re-signifcation provided by Paul. The valorised linguistic repertoire offered by the discourse of circumcision, is not circumvented; as a matter of fact, with its insistence on superior manhood, superior ethnos, engendered, ethnical and educational obligations, the values of the current Roman Empire are replicated. Yet resistance cannot be denied when circumcision is redefined by the implantation of another bodily part's discourse, namely the heart, thereby foregrounding the necessity of male rationality or reasonableness, and insisting of a redefinition of Jewishness, a redefinition on what the 'true Jew' constitutes. According to Paul, "he is a Jew who is one inwardly, and real circumcision is a matter of the heart, spiritual and not literal" (2:29). In an argument of dissociation circumcision is not rejected, but a particular strand of the Deuteronomic tradition is used to interiorise this marker of gender, ethnicity and epistemic superiority. The phallogocentric is not subverted, but is redefined, as can also be seen by the use of Abraham as an exemplum (Romans 4) and the deployment of the circumcision rite as an event which arrived at a later stage of his life.

Although the objective of this article is more to demonstrate by way of example how rhetorics of the body functioned in the production of the Romans letter, and not to specifically focus on historical questions concerning the letter to the Romans, it may be worthwhile to consider the non-Jewish implied audience of this letter, the association between manliness, wisdom and knowledge, the necessity of opening the boundaries of Jewish ethnicity, as well as the aesthetic disapproval of circumcision as signifier of anything but a topic of parody (see Dover 1978:129; Richlin 1992:132). Not only does Paul identify with a Roman corporal epistemic, but an exclusive Jewish identity structured by a particular rhetoric of the body is problematised. Instead of political-correctly in postHolocaust enthusiasm hailing Paul as opponent of the Roman imperial regime, shifting opposition away from Judaism, it could be asked whether his apostrophe in Romans 2-3 should not be seen as a colonising performance, playing up to a Roman implied audience who could have facilitated his projects of expansion (contra Horsley 2004)?

21 See Biesecker (1992) again. 


\section{The Role of Pneuma (Romans 8)}

Troy Martin (2006:126) concludes his essay on Paul's pneumatological statements as follows: "In their conception of the Spirit's entry and function in the human body, therefore, Paul's pneumatological statements reflect the physiology of pneuma in ancient medical texts, and these texts provide a productively coherent context in which to read Paul's statements about the spirit." Martin (2006:104-106) introduced his essay by referring to three approaches that claim to take context as point of departure, but does not pay any attention to the body in their discussion of Paul's pneumatological statements. Despite contextual claims, Dunn approaches the notion of spirit from a theological context, indicating that Paul's pneumatological statements are one of three aspects describing the beginning of salvation; Fee, from an experiential context, indicates that the Holy Spirit functions as an empowering presence, and Horn from a history of religious sphere, finds in the role of the Holy Spirit a functional and material down payment. Martin sees his contribution in providing another context, namely that of the body approached from the perspective of medical discourse.

There is of course an array of possibilities concerning the referentiality of pneuma which leaves us with a rather instable notion. ${ }^{22}$ Yet when medical discourse is taken into consideration, a few aspects that may provide with an alternative explanatory model emerge.

With liquids and solids, pneuma functions as 'breath' in the domain of nutrition (2006:107). Owing to the porosity of the body, and owing to the extreme fineness of pneuma, it can actually access the body anywhere, but its main points of access appear to be the mouth and nose, with the stomach also a possibility. Although nutrional it is a quality of respiration, and it may function to 'form the soul' (Asclepiades), to "cool the innate heat of the body" (Philistion and Diocles), to "cool the innate heat of the body and serve as nourishment" (Hippocrates - Martin 2006:108). Martin discusses the ancient physiology of the pneuma referring to its points of bodily entry, via the mouth, nose, pores of the skin or the digestive system, the manner in which it is responsible for movement, as well as its association with rationality, health and its mandate to impart life to the body (2006:107-114). Although it would not be possible to establish direct dependency, he very convincingly demonstrates several instances where particular views on the body must have informed Paul's position on issues such as the reception of the Spirit oro-nasally (Gal 3:15 ), through the pores of the skin (1 Cor 12:13a), the digestive system ( 1 Cor 12:13b probably, 1 Cor 10:3-4 definitely (2006:115-119). In a similar manner can be illustrated how Paul appropriated ancient pneumatological physiology in some of his views on movement and rationality (for example ${ }^{23}$ Rom $2: 29 ; 5: 5 ; 8: 4,5,14$ ), as well as on spiritual health and life (1 Cor11:27-34; Rom 8:2,11). Martin's work contributes to show the extent to which constructions of the body, in this case, via medical discourse filtered through and determined other discourses in the making of early Christianity.

22 See Singer (1997:xii) who observes that "Pneuma has connotations in the ancient world as distant as those of the compressed air that was used in certain Hellenistic mechanical devices and the 'Holy Spirit' (pneuma hagion) of the New Testament." Although it is possible to agree on its disparate referentiality, it is a question whether this observation has not also been determined by a Cartesian body versus mind dichotomy, a dichotomy between physical and spiritual? Would it not also be possible to analyse the notion of pneuma as a product of power in different sites of emergence and the 'holy Spirit' not as a theological concept but as a product and productive of the body inscribed into its relations of power?

23 Martin also refers to examples from other Pauline epistles - I have selected only those from the Romans letter. 
However, a rhetoric of the body using what has been offered can advance a little further. Although Martin refers to the life-giving function of the pneuma, he stops short of its function in the reproductive sphere. Galen lived almost a century after Paul, and the objective is not to illustrate similarities in thought between Paul and Galen, but rather to argue that a configuration of pneuma, blood, brain, heart, life-giving, health, self-control, and manliness existed for several centuries before Paul and Galen cannot really be isolated to one specific sphere of knowledge, but was differently appropriated and variously problematised. I use Galen, not only because his views on pneuma reach back as far as Plato, but also because he provides with a particular demarcation of discursive lines that make 'sense.'

For Galen such a close relationship exists between the soul and the body, that the soul can be seen as dependent on the body, can even be seen as function of the body (Siegel 1976:4; Brain 1986:5) - it is an agency through which Nature rules the body and it makes use of the three centres of the body, namely the liver which influences the body through the veins, the heart through the arteries and the brain through the nervous system. In this sense he follows Plato's 'tripartite soul' consisting of a rational part, situated in the brain, a spirited part, situated in the heart, and a desiderative part, allocated to the liver (Singer 1997:xi). Martin (2006:107) has quite correctly indicated that pneuma forms part of nutrition. We have to understand how the digestive system was seen to operate. ${ }^{24}$

Food that has been digested in the stomach is turned into 'nutritious blood' in the liver and from here transported, via the veins, to the different parts of the body in measurements appropriate to the requirement of the particular bodily part. A certain amount of this nutritious blood is also attracted to the heart, where it passes through the right side and then passes through "perforations in the intra-ventricular septum to the left side" (Nutton 2004:233) Here it is joined by 'refined air', called pneuma, which has been transported from the lungs along the pulmonary vein (2004:233). In the left ventricle of the heart, the mixture of blood and pneuma is concocted by the heat of the heart to produce an even thinner blood to flow via the arteries to the rest of the body in order to "vivify the body by its "vital spirit" (2004:234), that is, pneuma zotikon. A small amount of blood however, passes through the base of the brain which produces an even more refined version which can be called 'psychic pneuma' (pneuma psychikon). The spirited power (pneuma zôtikon) which is formed by a concoction of blood and air, set in motion by heat, in the left ventricle of the heart, and which provides blood's power, has the desire to effect "freedom, victory, power and authority, reputation and honour" (Singer 1997:152). ${ }^{25}$ The pneuma psychikon is responsible for sensation, voluntary movements of parts, imagination, memory, knowledge and thought (Brain 1986:6). It is clear that there is a connection between the 'spirit,' the 'heart' as centre of cognition, but also with the brain. Whichever of the two was chosen both related to rationality and consciousness, and life, 'life,' as in life-giving, and mobility.

24 A brief summary of the process is given by Galen himself in his polemic with Platonists. He argues that "everything eaten is first of all 'drunk down' into the stomach, where it undergoes a preliminary process of transformation, then received by the veins which lead from the liver to the stomach, and that it then produces the bodily humours, by which all other parts, including the brain, heart and liver, are nourished. But in the process of nutrition these parts become hotter than normal, or colder, or wetter, in accordance with the nature of the humours which predominate" (iv.807 - Singer (1997:xliii) relies on Kühn's compilation of Galen's works (Opera omnia Claudii Galeni). One has to bear in mind that the circulatory system has not yet been discovered; Galen consequently surmises that the flow of the blood in both arteries and veins are away from the centre to the periphery and as a depletion takes place on the periphery it is again replaced at the centre (Brain 1986:6).

25 Singer's translation of The soul's dependence on the body at iv.772. 
It is seen as agency, as a power that causes movement, as a possibility for explaining the origin of life. Outside the body it may be called air, but inside the body breath, and in both cases it functions as condition to movement.

Not only was the vital spirit responsible for maintaining and ensuring healthy balanced body, consisting of a rational soul, but it was also responsible for the production of life. In a kind of distillation process the vital spirit travels with blood throughout the body, visiting the heart and the brain on its journey to the genital area. The escalating movement in the sexual act increases the heat of the body to such an extent that red blood turns into white semen, in its turn lending the most refined quality to spirit enabling its life-giving powers. Brown (1998:123) formulates in typically apt fashion: "Here were little fiery universes, through whose heart, brain, and veins there pulsed the same heat and vital spirit as glowed in the stars. To make love was to bring one's blood to the boil, as the fiery vital spirit swept through the veins, turning blood into the whitened foam of semen. It was a process in which the body as a whole - the brain cavity, the marrow of the backbone, the kidneys and the lower bowel region - was brought into play, 'as in a mighty choir'. The genital regions were mere points of passage. They were the outlets of a human Espresso machine. However, it also becomes clear why sexual activity was often seen as damaging, because since the body was seen as a container, the body could be depleted of its vital spirit" (see Foucault 1984:116). ${ }^{26}$

A rhetoric of the body exposes how the dominant symbolic order with its phallogocentric perspective was implanted on the body. The concept pneuma is coined over a long period of time as the quintessential sign with which to depict manliness. Primary social category for the description of a man is his activeness, whether that be within the military sphere, the bedroom, the market-place or in the assembly; as a matter of fact, even the possibility of a beard or the brownish colour of his skin served as proof of the adult male as active. In the concept, pneuma man as active can be seen - pneuma moves, traverses through the body and causes to move. Repeatedly refined it consists of the capacity even to penetrate. Moreover, its very origin is to be located in the fundamental element which was specifically typified as male, namely heat, and its infusion of the humour, also specifically related to masculinity, blood. Yet another social category, specifically typified as male, was rationality. The physical is transplanted on to the level of morality, the sphere of male virtues. A man whose spirit is constituted by the correct proportions stands for victory, honour, power, imagination, good memory, knowledge and thought. It stands to reason that the journey of a proportionate amount of vital pneuma to the brain and its further refinement at its base would provide an explanation why the possession of vital spirit would also provide rationality. Finally, man as the primary force behind procreation is signified by semen containing the vital spirit necessary for procreation and the continuation of life, despite women who were also seen to produce semen, yet without the necessary ingredient of the vital spirit. The inscribing of male social categories on the pneuma as derivative of the utmost requirements of life, namely breath, blood, and heat, a forceful 'can-do-ness' was provided to the male body, a naturalness to its status and power, a superiority which only could serve as criterion of what bodiliness can be.

It is this constructed body, this manufactured pneuma, which constituted part of what can be called the 'unconscious knowledge' of Paul, or in Bourdieuan terminology, his

26 See for example Diocles, probably a contemporary of Aristotle (Nutton 2004:121), who claimed that since male semen was drawn from the brain, frequent sexual encounters could be dangerous since the body could become depleted of vital pneuma (2006:123). 
habitus. Constituted by a diversity of discursive practices and not necessarily always in agreement, the Graeco-Roman world offered Paul a repertoire of bodily terminologies and strategies valorised by gender, ethnic, social and reputational hierarchies. The notion of pneuma was indeed part of a regulatory practice, materialising the male body, as the body. But as product of power, it also gave birth to power. As quintessential characteristic of the male body, it was radicalised to become deified as the 'holy Spirit,' and it returned to create a superior community of males.

That Paul availed himself of discourse concerned with the pneuma deriving from the world of healing in the Roman Empire, can be seen in the way the Spirit gains access to bodies, inhabits them, empowers them, gives them a new life, makes them adhere to a lifestyle corresponding to a privileged rationality. The Spirit has gained access to the bodies of the non-Jewish implied audience of Paul, and has made their bodies its abode; it has become a life-giving, enabling power of rationality transforming their bodies and lifestyle to a life of a particular rationality $(8: 9,11,15,16)$. Moreover, his notion of pneuma is linked with life-giving and procreation $(\mathrm{Rm} 8: 2,6,10,11,13,14,15,16,17,23)$. The metaphor of the household functions as framework within which the 'procreative' and lifegiving function of the Spirit is spelt out. But it is also cosmologically extended when the whole of creation is portrayed as waiting and enduring in the agony of a birthing process (8:21-23), with the Spirit as the sustaining and releasing principle. The engendered, ethnic and social hierarchies of the Graeco-Roman world, have neither been rejected nor resisted, but have been deployed in a radicalising manner. The pneuma now gives life to 'sons of God' $(8: 14-15,19,23,29),{ }^{27}$ and creates legacy of a 'sonship,' with recognition of a God who can be called 'Father' $(8: 15-16)$. The spirit also enables action and movement. Those who have not been entered by the Spirit, are depicted as in a state of incapacity and weakness $(8: 3,7,8)$, whereas those inhabited by the Spirit have been enabled $(8: 13,26)$, and especially enabled to endure. However, a process of liberation not only for the cosmos, but especially also for the 'sons of God' has been set in motion $(8: 2,15,21,23,28-30)$. The Spirit is depicted as having set a process in motion that will lead to the birth of a new cosmos $(8: 21-25)$. It should be borne in mind that the ability to act was the specific characteristic of the elite, adult Roman male. The depiction of the entire cosmos as in a state of birthing and suffering, characteristics typical of the passive female, contributes to a recognition of masculinity in the liberating action of the Spirit. The Spirit is finally consistently associated with rationality and reasonableness $(8: 5,6,15,26,27)$, with sons of God 'in the know' $(8: 15,22,24,25,28)$ with the capacity of deliberation $(8: 16)$ and with bodies reflecting a lifestyle of rationality $(8: 4,13)$. Rationality as typical of the elite, adult, male, the vir bonus, should not go unnoticed. This is confirmed when we recall Paul's redefinition of circumcision as a circumcision of the heart by the Spirit, reflected in a lifestyle that can be assigned to the 'true Jew.' "Walking according to a singleness of the heart" and "walking in the Spirit" both locate the implied audience within the sphere of the 'true, male Jew,' there by showing a concern to shift boundaries through a redefinition of identity markers.

Briefly referring to the non-Jewish implied audience of this letter, Paul's views on the spirit functions to effect a solidarity among the followers of this new movement. There is

27 The use of the more gender neutral t eknon should not detract from the default persistence of the manly body. No attempt is made to deploy t eknon in a more gender neutral sense; moreover, the possibility should be entertained that its greater inclusiveness relates to the metaphor of the household, but more particularly also to the possibility of daughters and wives being included in the estate of the husband in the case of manus or the paterfamilias in the case of sine manu (see Skinner 2005:202). 
here no resistance offered to a Roman Empire, but rather a somatication of a Roman habitus constituted by medical practice that has developed over centuries. Social hierarchies of gender are not resisted but enforced, even radicalised, and the panoptic vision of the elite Roman male citizen is enforced. In the Roman non-Jewish implied audience is found a perfect, 'true' example of the Roman bonus vir, but this time as a 'son of God' located in divine continuity.

\section{Conclusion}

1. Approaching early Christian material from a rhetoric of the body requires shifting from text to discourse. However, this shift enables a movement away from the author, authorial intention, the interpreted meaning of the text, to those practices that have played a constitutive role in its formation. Since performativity becomes the articulating principle in which this shift takes place, a rhetoric of the body also opens up a new field in which the current effects of biblical discourse must become part of the disciplinary endeavour.

2. A rhetoric of the body as interpretative paradigm problematises not only the dichotomy between mind and body, but it also demonstrates how thought is corporal, how the theological may be the product of bodily constructions. As such it confirms discontinuity rather than continuity and it problematises the relating or harmonising of textual material in continuity. Moreover, owing to the disruption of the dichotomy between mind and body and to the over-valorisation of mind, it requires rethinking or reimagining many of our taken-for-granted categories. One of these would be the way in which biblical rhetorical critics operate, using classical rhetorical techniques as material for heuristic analysis.

3. A rhetoric of the body as interpretative framework for the Romans letter illustrates how the body functioned as epistemic source to naturalise formations of identity. At the same time it established the body as site for the contestation of different regimes of power, as a site where dominant discourse can be entrenched, modified, resisted, but also as a site from where contending discourses can be excluded. Concerning the letter to the Romans, there appears to be a radicalisation of the Roman habituated body. The possibility that this radicalisation was motivated because of the concern to provoke identification with the Pauline mission should not be excluded.

\section{BIBLIOGRAPHY}

Biesecker, Barbara 1992. Michel Foucault and the Question of Rhetoric. Philosophy and Rhetoric 25(4):351-364.

Bourdieu, Pierre 1990. The Logic of Practice. Translated by Richard Nice. Stanford: Stanford University Press.

Brain, P 1986. Galen on bloodletting: A study of the origins, development and validity of his opinions, with a translation of the three works. Cambridge: Cambridge: University Press.

Brown, Peter 1988. The Body and Society: Men, Women and Sexual Renunciation in Early Christianity. London: Faber and Faber.

Butler, Judith 1993. Bodies that Matter: On the Discursive Limits of 'Sex.' New York and London: Routledge. 
Butler, Judith 1989. Foucault and the Paradox of Bodily Inscriptions. The Journal of Philosophy 86(11):601-607.

Carson, Anne 2002. Dirt and Desire: The Phenomenology of Female Pollution in Antiquity. Pages 77-100, in Constructions of the Classical Body. Edited by James I. Porter. Ann Arbor: The University of Michigan Press.

Condit, Celeste 1999. The Materiality of Coding: Rhetoric, Genetics, and the Matter of Life. Pages 326-356, in Rhetorical Bodies. Edited by Jack Selzer and Sharon Crowley.

Dillon, John and Gergel, Tania 2003. The Greek Sophists. Translated by John Dillon and Tania Gergel. London: Penguin Books.

Dover, K J 1978. Greek Homosexuality. London: Duckworth.

Dunn, James D G 1988. Romans 1-8. Word Biblical Commentary 38A. Dallas: Word Books.

Eilberg-Schwartz, Howard 1990. The Savage in Judaism: An Anthropology of Israelite Religion and Ancient Judaism. Bloomington and Indianapolis: Indiana University Press.

Flemming, Rebecca 2000. Medicine and the Making of Roman Women: Gender, Nature, and Authority from Celsus to Galen. Oxford: Oxford University Press.

Foucault, Michel 1978. History of Sexuality. Vol 1. An Introduction. Translated by R Hurley. Harmondsworth: Penguin Books.

Foucault, Michel 1984. History of Sexuality. Vol 2. The Use of Pleasure. Translated by R Hurley. Harmondsworth: London.

Foucault, Michel 1988. Technologies of the Self: A Seminar with Michel Foucault. Edited by Luther H Martin, Huck Gutman and Patrick Hutton. Amherst: The University of Massachusetts Press.

Foucault, Michel 2001. Fearless Speech. Edited by Joseph Pearson. Los Angeles: Semiotext(e).

Gaca, Kathy L 2003. The Making of Fornication: Eros, Ethics and Political Reform in Greek Philosophy and Early Christianity. Berkeley: University of California Press.

Gaonkar, DP 1990. Rhetoric and its Double: Reflections on the Rhetorical Turn in the Human Sciences. Pages 341-366, in The Rhetorical Turn: Invention and Persuasion in the Conduct of Inquiry. Edited by HW Simons. Chicago: Chicago University Press.

Glancy, Jennifer 2010. Corporal Knowledge: Early Christian Bodies. Oxford: Oxford University Press.

Gleason, Maud W 1995. Making Men: Sophists and Self-Presentation in Ancient Rome. Princeton: Princeton University Press.

Greenblatt, Stephen 1997. Mutilation and Meaning. Pages 221-241, in The Body in Parts: Fantasies of Corporeality in Early Modern Europe. Edited by David Hillman and Carla Mazzio. New York: Routledge.

Horsley, Richard A 2004. Introduction. Pages 1-24 in, Paul and the Roman Imperial Order. Edited by Richard A. Horsley. Harrisburg: Trinity Press International.

Jewett, Robert, 2007. Romans: A Commentary. Hermeneia - A Critical and Historical Commentary on the Bible. Minneapolis: Fortress Press. 
Lausberg, Heinrich 1998. Handbook of Literary Rhetoric: A Foundation for Literary Study. Translated by Matthew T Bliss, Annemiek Jansen and David E Orton. Edited by David E Orton and R Dean Anderson. Leiden: Brill.

Malul, Meir 2002. Knowledge, Control and Sex: Studies in Biblical Thought, Culture and Worldview. Tel Aviv-Jaffa: Archaeological Center Publication.

Martin, Troy W Paul's Pneumatological Statements and Ancient Medical Texts. Pages 105-126 in, The New Testament and Early Christian Literature in Greco-Roman Context - Studies in Honor of David E Aune. Edited by John Fotopoulos. Leiden: Brill.

Mills, Sara 2003. Michel Foucault. London: Routledge.

Nutton, Vivian 2006. Ancient Medicine. London: Routledge.

Oksala, Johanna 2007. How to Read Foucault. London: Granta Books.

Richlin, Amy 1992. The Garden of Priapus: Sexuality and Aggression in Roman Humor. Rev. (ed.) New York: Oxford University Press.

Schiappa, E 1992. Rhetorikê: 'What's in a Name?' Toward a Revised History of Early Greek Rhetorical Theory. The Quarterly Journal of Speech 78:1-15.

Siegel, RE 1976. Galen on the affected parts. Basel: S Karger.

Singer, PN 1997. Galen:Selected Works. Translated with an Introduction and Notes by PN Singer. Oxford: Oxford University Press.

Skinner, Marilyn 2005. Sexuality in Greek and Roman Culture. Malden: Blackwell Publishing.

Stowers, Stanley K 1979. The Diatribe and Paul's Letter to the Romans. Chico: Scholars Press.

Tell, Dave 2010. Rhetoric and Power: An Inquiry into Foucault's Critique of Confession. Philosophy and Rhetoric 43(2):95-117.

Vander Stichele, Caroline and Penner, Todd 2009. Contextualizing Gender in Early Christian Discourse: Thinking beyond Thecla. London and New York: T\&T Clark.

Vorster, Johannes N, 2008. Rhetorically reflecting on 'Jesus' research. Theologia Viatorum 32(2):6-48

Vorster, Johannes N, 2009. Rhetorical Criticism. Pages 505-578 in Focusing on the Message: New Testament Hermeneutics, Exegesis and Methods. Edited by Andrie B du Toit. Pretoria: Protea. 